University of Massachusetts Amherst

ScholarWorks@UMass Amherst

Chemistry Department Faculty Publication Series

Chemistry

1986

\title{
Flow Injection Atomic Absorption Spectrometry: The Kinetics of Instrument Response
}

\author{
J.M. H. Appleton \\ Loughborough University of Technology \\ Julian Tyson \\ University of Massachusetts Amherst
}

Follow this and additional works at: https://scholarworks.umass.edu/chem_faculty_pubs

Part of the Chemistry Commons

\section{Recommended Citation}

Appleton, J. M. H. and Tyson, Julian, "Flow Injection Atomic Absorption Spectrometry: The Kinetics of Instrument Response" (1986). Journal of Analytical Atomic Spectrometry. 1294.

Retrieved from https://scholarworks.umass.edu/chem_faculty_pubs/1294 


\title{
Flow Injection Atomic Absorption Spectrometry: The Kinetics of Instrument Response
}

\author{
John M. H. Appleton and Julian F. Tyson \\ Department of Chemistry, University of Technology, Loughborough, Leicestershire LE11 3TU, UK
}

\begin{abstract}
The concept of dispersion coefficient is discussed with particular reference to flow injection atomic absorption spectrometry where the detector contributes appreciably to the analytical signal characteristics. Single- and parallel-tank models of instrument response are developed and critically examined. The progress made to date by investigators of nebuliser performance is briefly reviewed prior to developing a semi-empirical extended-tank model of instrument response. The capabilities of this model are explored by deriving a set of equations for instrument response, and comparing the predictions with experimental results. Agreement is generally good. Advantages of the modelling approach are discussed.
\end{abstract}

Keywords: Flow injection; atomic absorption; kinetics; instrument response

Flow injection (FI) ${ }^{1}$ is an elegant and versatile technique that continues to attract increasing attention from analysts worldwide. Of fundamental importance in FI is an understanding of the process of dispersion of a sample in a carrier stream under conditions of laminar flow. By controlling dispersion, the analyst may manipulate small volumes of samples and reagents with speed, simplicity and precision to obtain analytical results more efficiently in terms of time, labour and materials consumed. The extent to which dispersion occurs in an FI manifold is usually quantified by the dispersion coefficient $D$, as defined by equation (1)

$$
D=\frac{C_{\mathrm{m}}}{C_{\mathrm{p}}}
$$

where $C_{\mathrm{m}}$ is the original analyte concentration and $C_{\mathrm{p}}$ is "the analyte concentration at the maximum of the peak."2 (All symbols used are explained in Table 1.) More recently, in connection with the miniaturisation of FI apparatus, Růžička and Hansen ${ }^{3}$ have introduced the concept of dispersion factor, defined as the volume required to give $D=2$ divided by the

Table 1. List of symbols used in text

\begin{tabular}{|c|c|c|c|}
\hline$A ; A_{\mathrm{r}}$ & & . & $\begin{array}{l}\text { Absorbance; corresponding to } C_{\mathrm{m}} \text { and } C_{\mathrm{p}} \text {, } \\
\text { respectively }\end{array}$ \\
\hline C & & & $\begin{array}{l}\text { Concentration (in a flowing steam, integrated } \\
\text { across the entire stream normal to the flow) }\end{array}$ \\
\hline$C_{\mathrm{i}} ; C$ & & . & $\begin{array}{l}\text { Instantaneous concentration input; injected } \\
\text { and peak concentrations of stream }\end{array}$ \\
\hline$D_{\mathrm{d}}, L$ & & . . & $\begin{array}{l}\text { Detector, manifold and response dispersion } \\
\text { coefficients }\end{array}$ \\
\hline & & . . & Volumetric fraction of stream flowing via path $i$ \\
\hline & & & Gradients of graph when $t=0$ and $\infty$ \\
\hline$H_{\mathrm{m}}$, & & . & $\begin{array}{l}\text { Detector responses corresponding to } C_{\mathrm{m}} \text { and } \\
C_{\mathrm{n}} \text {, respectively }\end{array}$ \\
\hline$h, h^{\prime}$ & . . & . & $\begin{array}{l}\text { Value of } u / V, u / V^{\prime} \text { for hypothetical and real } \\
\text { tanks, respectively }\end{array}$ \\
\hline$k$ & . . & . & Constant relating absorbance and concentration \\
\hline$m$ & . & .. & Analyte mass (in tank) \\
\hline$p$ & . & . & $\begin{array}{l}\text { In the model, the fraction of the sample stream } \\
\text { contributing to the analytical signal }\end{array}$ \\
\hline & . & . & Diluent flow through the hypothetical tank \\
\hline$Q$ & . & . & Total flow through hypothetical tank \\
\hline$t, t_{\mathrm{p}}$ & . & . & Time and time to reach peak response \\
\hline$t^{\prime}, t_{n}^{\prime}$ & & & $\begin{array}{l}\text { Peak width at constant height and } 1 / n \text { of peak } \\
\text { height }\end{array}$ \\
\hline$u$ & . & . & Volumetric flow-rate of carrier, sample \\
\hline$u_{\max }$ & . & & Flow-rate giving highest peak for given $V_{\mathrm{i}}$ \\
\hline & . . & & $\begin{array}{l}\text { Volume of hypothetical tank forming basis of } \\
\text { model }\end{array}$ \\
\hline$V^{\prime}$ & & & Volume of real mixing tank \\
\hline$V_{\mathrm{i}}$ & & & Sample volume injected \\
\hline
\end{tabular}

volume of the flow line. Whichever parameter is used to quantify dispersion, $C_{\mathrm{p}}$ has to be known.

However, the transient concentration $C_{\mathrm{p}}$ can only be determined indirectly. For an ideal detector (one which accurately reproduces the concentration profile of the determinand entering the detector) equation (1) may be extended to yield

$$
D=\frac{C_{\mathrm{m}}}{C_{\mathrm{p}}}=\frac{H_{\mathrm{m}}}{H_{\mathrm{p}}}
$$

where $H_{\mathrm{m}}$ and $H_{\mathrm{p}}$ are the instrument responses corresponding to $C_{\mathrm{m}}$ and $C_{\mathrm{p}}$, respectively.

Thus, although the dispersion coefficient, an important FI parameter, has been defined by the concentration ratio $C_{\mathrm{m}} / C_{\mathrm{p}}$, it can only be determined from the response ratio $H_{\mathrm{m}} / H_{\mathrm{p}}$. For many FI techniques, this constitutes a valid and convenient method of determining dispersion coefficient. However, despite an increasing number of papers involving flow injection atomic absorption spectrometry (FI-AAS), little has been said about the error of extending the practice to this field. This application of the concept of dispersion coefficient therefore requires clarification, particularly for the benefit of newcomers to this promising extension of atomic absorption spectrometry (AAS). Certain difficulties arise when detector response is non-ideal, as is frequently so in FI-AAS.

Detectors for FI are usually flow-through types, designed to cause minimum disturbance of the flowing stream, so that detector contribution to the over-all signal is negligible (i.e., the dispersion coefficient due to the detector, $D_{\mathrm{d}}$, is unity). The performance of such detectors is close to ideal when the detector response is linear with respect to concentration and rapid. Used as an FI detector, the atomic absorption spectrometer has neither of these qualities. Orderly sample flow is totally disrupted during nebulisation to create an aerosol suitable for flame atomisation. The resulting analytical signal, $H_{\mathrm{p}}$, relates to peak concentration of aerosol entering the flame rather than to $C_{\mathrm{p}}$. The process of aerosol generation and conditioning takes time, so that response is not instantaneous. In addition, spectroscopic limitations restrict the linear range of AA instruments, causing calibration plots to deviate towards the concentration axis. As a result of these peculiarities, the AA spectrometer behaves as a non-ideal FI detector.

If a discrete sample plug is placed in the carrier stream close to an ideal detector so that no appreciable manifold (all flow regions excluding those subject to detector effects) dispersion occurs, the resulting manifold dispersion coefficient will be unity.

As will be shown later, results of this experiment for FI-AAS confirm that the AA spectrometer is not an ideal 
detector. Clearly, the ratio $A_{\mathrm{m}} / A_{\mathrm{p}}$ does not reflect manifold dispersion, but some apparent dispersion, due solely to the detector. In FI-AAS work, therefore, it is important to distinguish between this apparent dispersion due to the response characteristics of the spectrometer and real dispersion occurring in the flow manifold preceding the detector.

In conventional use, AA spectrometers furnish steady-state absorbance signals from which concentrations are derived. In this context, "concentration" refers to the concentration of the sample entering the nebuliser, i.e., the spectrometer is regarded as a "black box" detector that enables the concentration of a sample input to be determined. What happens to the sample inside the box is of secondary importance to the majority of users. Adopting the same approach in FI-AAS we shall define $C_{\mathrm{p}}$ as the maximum concentration of determinand in the stream immediately prior to entering the nebuliser. Defined in this way, the ratio $C_{\mathrm{m}} / C_{\mathrm{p}}$ is clearly a property of the FI manifold and will be termed the manifold dispersion coefficient, $D_{\mathrm{m}}$, where

$$
D_{\mathrm{m}}=\frac{C_{\mathrm{m}}}{}
$$

In conventional atomic absorption work, the sample must be aspirated for several seconds before a steady-state readout is obtained. The delay caused by the response time is usually acceptable so long as sufficient sample is available to produce the steady-state absorbance. The initial dynamic response of the instrument is explicitly ignored and no allowance has to be made for it. Only steady-state absorbance is read, and this relates directly to input concentration. With transient concentration profiles such as those existing in the flowing streams in FI-AAS, steady-state conditions are seldom attained, so that the effects of instrument response cannot be ignored. The signal is no longer a simple function of the sample concentration $C_{\mathrm{m}}$ (as in conventional work), but also depends upon the injected volume, $V_{\mathrm{i}}$ and the sample flow-rate, $u$.

To distinguish $D_{\mathrm{m}}$ from the response ratio $A_{\mathrm{m}} / A_{\mathrm{p}}$, the latter will be termed the response dispersion coefficient, $D_{\mathrm{r}}$, so that

$$
D_{\mathrm{r}}=\frac{A_{\mathrm{m}}}{A_{\mathrm{p}}}
$$

Thus $D_{\mathrm{r}}$ includes contributions from both $D_{\mathrm{m}}$ and $D_{\mathrm{d}}$, i.e.,

$$
D_{\mathrm{r}}=f\left(D_{\mathrm{m}}, D_{\mathrm{d}}\right)
$$

In particular, for the ideal detector $\left(D_{\mathrm{d}}=1\right)$ we have $D_{\mathrm{r}}=D_{\mathrm{m}}$; whilst, in situations where manifold dispersion is negligible $D_{\mathrm{r}}$ $=D_{\mathrm{d}}$. The detector dispersion coefficient $D_{\mathrm{d}}$ is thus confirmed as the value of $A_{\mathrm{m}} / A_{\mathrm{p}}$ when manifold dispersion is negligible. These concepts of dispersion coefficients might be usefully applied to other non-ideal FI detectors (e.g., slow-response potentiometric detectors).

Equation (5) presents a challenge, as it embodies the idea of compounding dispersion coefficients. Although the topic was broached by Růžička and Hansen ${ }^{2}$ more than six years ago, little quantitative progress appears to have been made. Yet the subject has considerable appeal. An understanding of it might enable manifold dispersion coefficients to be measured by FI-AAS methods. On a more general basis, it would be very convenient if one could plan an FI systemby theoretically combining the dispersion coefficients of the various components prior to experimental trial. The question of environment also needs to be resolved: is the dispersion coefficient of a single component constant, or does it depend upon the position of that component in combination with others? The existing theory [equations (6 and 7)] suggests that the dispersion coefficient of a $10 \mathrm{~cm}$ length of FI tubing depends upon whether it constitutes the first $10 \mathrm{~cm}$ or the last $10 \mathrm{~cm}$ of a $20 \mathrm{~cm}$ length of similar tubing.

Rủžička and Hansen, ${ }^{2}$ on the basis of the definition of dispersion coefficient, proposed that a series of $n$ components, having individual dispersion coefficients $D_{1}, D_{2}, \ldots D_{n}$, combined to produce an over-all dispersion coefficient, $D$, where

$$
D=D_{1} \times D_{2} \times \ldots D_{n} \ldots
$$

However, this proposal is not consistent with their "Rule 5," which states that the dispersion coefficient of the sample zone is proportional to the square root of the distance travelled. They have recently proposed ${ }^{3}$ that the effect of changing the length of the flow channel may be better described on the basis of dispersion factor rather than dispersion coefficient. Our experimental results support Rule 5 (but only when the sample volume is small), which may be expressed as equation (7)

$$
(D-1)=K L^{\frac{1}{2}}
$$

where $K$ is a constant. It should be noted that the equation has to have the property of $D=1$ when $L=0$.

Thus for tubes of equal diameters and lengths $L_{1}, L_{2}, \ldots L_{n}$

$$
\begin{gathered}
\left(D_{1}-1\right)^{2}=K^{2} L_{1} \\
\left(D_{2}-1\right)^{2}=K^{2} L_{2} \\
\vdots \\
\left(D_{n}-1\right)^{2}=K^{2} \dot{L}_{n}
\end{gathered}
$$

and applying equation (7) to the series combination yields

$$
(D-1)^{2}=K^{2}\left(L_{1}+L_{2}+\ldots L_{n}\right)
$$

i.e.,

$$
(D-1)^{2}=\left(D_{1}-1\right)^{2}+\left(D_{2}-1\right)^{2}+\ldots\left(D_{n}-1\right)^{2}
$$

It is suggested that this "tubes in series" equation might form a suitable basis for a quantitative approach to combining dispersions coefficients. Applying equation (8) to the combination of an FI manifold of dispersion coefficient $D_{\mathrm{m}}$ and a non-ideal detector of dispersion coefficient $D_{\mathrm{d}}$ enables equation (5) to be re-written as

$$
\left(D_{\mathrm{r}}-1\right)^{2}=\left(D_{\mathrm{m}}-1\right)^{2}+\left(D_{\mathrm{d}}-1\right)^{2}
$$

which is also currently under investigation. The present work, however, is concerned exclusively with detector response; that is, it seeks to account for the detector's contribution to the signals observed in FI-AAS.

\section{Instrument Response Theory}

\section{Use of Physical Models}

The scope of this investigation spans the areas of dispersion in FI systems and instrument response in atomic absorption. Both subjects have attracted the earnest attention of numerous researchers in recent years, yet have resisted accurate mathematical description. The difficulties centre around the complex and multivariate processes involved. Some of these are not well understood, except perhaps in terms of ideal behaviour, to which the real system seldom conforms. Even this treatment frequently produces equations that can only be solved by making further restrictive assumptions. In consequence, the solutions are often partial or conditional approximations, and may involve parameters not readily related to the experimental variables. Examples of various treatments of the problems encountered in dispersion studies may be found in the work of Růžička and Hansen, ${ }^{2,3}$ Betteridge, ${ }^{4}$ Taylor, ${ }^{5}$ Tijssen, ${ }^{6}$ van den Berg et al.,7 Reijn et al., ${ }^{8,9}$ Vanderslice et al. ${ }^{10}$ and Gomez-Nieto et al. ${ }^{11}$. Despite the dedicated efforts of these and other workers it is still not possible to write an expression for dispersion coefficients in terms of sample properties, tube dimensions and operating conditions.

The extensive work on AA response falls within two broad categories: aerosol generation, which includes investigations by Castleman, 12 Nukiyama and Tanasawa, ${ }^{13}$ Lane, ${ }^{14}$ Mugele and Evans, ${ }^{15}$ Bitron, ${ }^{16}$ Hrubecky ${ }^{17}$ and Mercer et al. ${ }^{18}$; and over-all nebuliser action, investigated by Stupar and Dawson, ${ }^{19}$ Willis, ${ }^{20}$ Cresser and Browner, ${ }^{21-23}$ Cresser and coworkers, ${ }^{24-26}$ Browner and co-workers ${ }^{27,28}$ and Gustavsson. 29,30 These excellent studies have furnished a wealth of information about aerosol quality and nebuliser performance, 


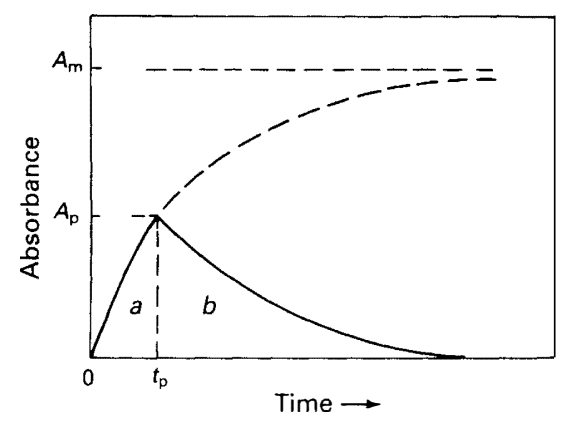

Fig. 1. Absorbance - time profile for discrete sample introduction according to the single-tank model

quantified by an array of specially defined parameters. Such information is invaluable in improving instrument performance. Nevertheless, it appears unlikely that absorbance will ever be directly expressed as a function of sample properties and nebulisation conditions. The intermediate steps are too many and too complex.

In such situations a simple physical model may find useful application. Such models, developed by trial, error and modification, are based on simulation and simplification rather than rigorous mathematical treatment. They provide a tangible summary of the real system at operational level, a set of parameters readily identified with the experimental variables, a basis for explanation, experiment, optimisation and forecast, and open the way to further theoretical development. It is for these reasons that a simple modelling approach is adopted as a means of circumventing the present impasse in this field.

\section{Single-tank Model}

Initial adjustment of an AA spectrometer involves selecting the values of various operating parameters to produce an acceptable instrument response. Thereafter the majority of these values are usually maintained constant whilst those selected for investigation are varied in turn. In the following discussion it is assumed that the instrument has been optimised and that the only experimental variables are to be sample concentration and volume injected.

Within its linear range, the response of an AA spectrometer to a step change in concentration (see Fig. 1) has been shown ${ }^{31}$ to resemble an exponential growth curve of the type

$$
A=k C_{\mathrm{m}}\left(1-\mathrm{e}^{-u t / V}\right) \ldots \quad \ldots \quad \ldots
$$

i.e., the instrument behaves as if the concentration step were modified by passage through a hypothetical well-stirred tank of volume $V$, prior to detection by an ideal detector. If $A=A_{\mathrm{m}}$ when $t=\infty$, then $A_{\mathrm{m}}=k C_{\mathrm{m}}$ and equation (10) may be re-written as

$$
A=A_{\mathrm{m}}\left(1-\mathrm{e}^{-u t / V}\right) \ldots \quad \ldots \quad \ldots
$$

or

$$
\ln \left(\frac{A_{\mathrm{m}}}{A_{\mathrm{m}}-A}\right)=\frac{u t}{V}
$$

Equation (12) may be used to test experimental data; a linear plot of $\ln \left[A_{\mathrm{m}} /\left(A_{\mathrm{m}}-A\right)\right]$ against $t$ indicates that the data conforms to the single-tank model. ${ }^{31}$

\section{Compound Exponential Model: Tanks in Parallel}

As will be shown later, the response of the detector used in our studies deviated somewhat from that predicted by the single-tank model.

If the flow of sample through the nebuliser does not correspond to ideally mixed flow, but rather to arbitrary flow, which appears likely considering the geometry of the typical spray chamber, then a spread of residence times occurs. Part of the sample passes almost unimpeded to the flame, whilst

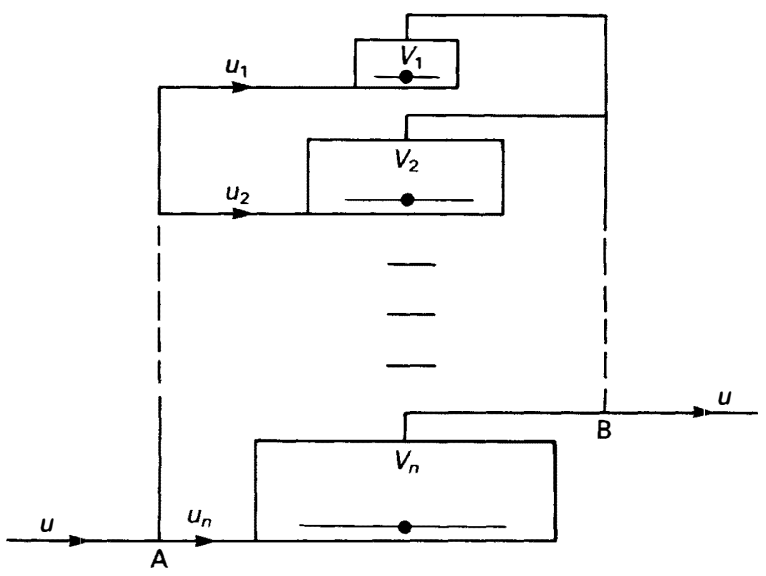

Fig. 2. Basis of the parallel-tanks model. The flow is considered to split at point $A$, flow through a number of well-stirred tanks and recombine at point $B$

other parts are held up for varying lengths of time. This type of flow may be modelled by a number of tanks in parallel, each accommodating a portion of the sample flow. The model illustrated in Fig. 2, consists of $n$ tanks of volumes $V_{1}-V_{n}$, connected in parallel. In this model, the fractions of the sample flowing through tanks $1,2, \ldots n$ are $f_{1}, f_{2} \ldots f_{n}$, respectively, so that $f_{1}+f_{2} \ldots f_{n}=1$.

The flow-rate through tank $i$ is $u_{i}$ where

$$
u_{i}=f_{i} u
$$

and for tank $i$ the effluent concentration is $C_{i}$ where

$$
C_{i}=C_{\mathrm{m}}\left[1-\exp \left(-f_{i} \frac{u t}{V_{i}}\right)\right]
$$

As mass is conserved at point $\mathrm{B}$, then

therefore

$$
u_{1} C_{1}+u_{2} C_{2}+\ldots u_{n} C_{n}=u C
$$

$$
\begin{aligned}
C= & \frac{u_{1} C_{1}+u_{2} C_{2}+\ldots u_{n} C_{n}}{u} \\
= & \sum_{i=1}^{n} f_{i} C_{i} \\
C=C_{\mathrm{m}_{i}} & \sum_{i=1}^{n} f_{i}\left[1-\exp \left(-f_{i} \frac{u t}{V_{i}}\right)\right]
\end{aligned}
$$

The corresponding decay curve on switching back from the steady state to water is

$$
C=C_{\mathrm{m}_{i}} \sum_{i=1}^{n} f_{i} \exp \left(-f_{i} \frac{u t}{V_{i}}\right) \quad \ldots \quad \ldots
$$

The simplest parallel-tanks model consists of just two tanks in parallel, so that equation (13) reduces to

$$
C=C_{\mathrm{m}}\left\{f_{1}\left[1-\exp \left(-f_{1} \frac{u t}{V_{1}}\right)\right]+f_{2}\left[1-\exp \left(-f_{2} \frac{u t}{V_{2}}\right)\right]\right\}
$$

The parallel-tanks approach provides an interesting and realistic model of the system response to step changes in concentration (see later). However, when applied to predict responses to more complex inputs, it produces complicated mathematical equations that are difficult to solve. In contrast, the single-tank model retains its essential simplicity and enables the determination of useful response equations for various inputs particularly where the response is observed soon after the input as in FI-AAS.

Where the over-all response dispersion coefficient $D_{\mathrm{r}}$ is dominated by an appreciable manifold dispersion coefficient $D_{\mathrm{m}}$, as may be so in FI-AAS, and is an essential condition for continuous dilution calibration ${ }^{32}$ work, the detector may be regarded as ideal as its contribution to the signal is negligible. For example, assuming that equation (9) is valid, for a system having $D_{\mathrm{m}}=10$ and $D_{\mathrm{d}}=1.5$, then $D_{\mathrm{r}}=10.01$. 


\section{Prediction of System Responses Using the Single-tank Model}

The basic postulate of the single-tank model is that the system responds as though the sample stream leaving the manifold passes through a small well-stirred tank prior to detection by an ideal detector. The analyte mass content of the model's hypothetical tank is given by the equation

$$
\frac{\mathrm{d} m}{\mathrm{~d} t}=u\left(C_{\mathrm{i}}-C\right)
$$

where $C_{\mathrm{i}}$ is the instantaneous concentration entering the tank and $C$ is the concentration in the tank, at time $t$. Division by $V$ yields

$$
\frac{\mathrm{d} C}{\mathrm{~d} t}=\frac{u}{V}\left(C_{\mathrm{i}}-C\right)
$$

However, within the linear range of the system response, $A=$ $k C$, then

$$
\frac{\mathrm{d} A}{\mathrm{~d} t}=\frac{u}{V}\left(k C_{\mathrm{i}}-A\right) \quad \ldots \quad \ldots \quad \ldots
$$

The general equation (16) is the fundamental single-tank model prediction of the system response to an instantaneous concentration input $C_{\mathrm{i}}$ to the nebuliser.

\section{Conventional aspiration, i.e., step concentration input}

When a sample of concentration $C_{\mathrm{m}}$ is aspirated, then $C_{\mathrm{i}}=C_{\mathrm{m}}$ $=$ constant and the absorbance - time relationship follows equation (11).

This predicts that the step concentration change generates an exponential increase in absorbance and that the maximum signal $A_{\mathrm{m}}$ is recorded only after an infinite time. However, for appropriate values of $u$ and $V, 0.999 A_{\mathrm{m}}$ is reached after $2.5 \mathrm{~s}$.

\section{Discrete sample introduction}

The single-tank model predicts that concentration may be determined using absorbance values recorded before the attainment of the steady state, provided that the response is observed after a fixed interval of steady sample flow. This principle is the basis of discrete sample nebulisation for which calibration is valid for both peak-height and peak-area modes. In accordance with equation (11) the peak absorbance $A_{\mathrm{p}}$, attained when a sample of concentration $C_{\mathrm{m}}$ is aspirated continuously for time $t_{\mathrm{p}}$ at flow-rate $u$, is given by

$$
A_{\mathrm{p}}=k C_{\mathrm{m}}\left[1-\exp \left(-\frac{u t_{\mathrm{p}}}{V}\right)\right] \ldots \quad \ldots
$$

As $t_{\mathrm{p}}$ is constant, then $A_{\mathrm{p}} \propto C_{\mathrm{m}}$.

The peak area is given by the sum of the two areas designated $a$ and $b$ in Fig. 1,

$a+b=k C_{\mathrm{m}}\left[\int_{0}^{t}{ }^{t} \mathrm{p}\left(1-\mathrm{e}^{-u t / V}\right) \mathrm{d} t+\int_{t_{\mathrm{p}}}^{\infty}\left(1-\mathrm{e}^{-u t} t_{\mathrm{p}} / V\right) \mathrm{e}^{-u t / V} \mathrm{~d} t\right]$ but as $t_{\mathrm{p}}$ is constant, peak area $\propto C_{\mathrm{m}}$. Thus, the model predicts that both peak height and peak area are valid measures of sample concentration.

Beyond the linear range of instrument response calibration graphs are curved, as for conventional aspiration.

\section{Continuous dilution calibration}

This technique employs a real mixing tank of volume $V^{\prime}$ to produce an exponential standard concentration - time profile. In response to a step change from zero to $C_{\mathrm{m}}$ in the concentration input to the tank, the effluent concentration has been shown ${ }^{32}$ to be

$$
C=C_{\mathrm{m}}\left(1-\mathrm{e}^{-h^{\prime} t}\right) \quad \ldots \quad \ldots \quad \ldots
$$

where $h^{\prime}=u / V^{\prime}$.

The detector response to an instantaneous input $C_{\mathrm{i}}$ is described by equation (16). Writing $u / V=h$, and substituting $C_{\mathrm{i}}=C$ from equation (18) yields

$$
\frac{\mathrm{d} A}{\mathrm{~d} t}=h\left[k C_{\mathrm{m}}\left(1-\mathrm{e}^{-h^{\prime} t}\right)-A\right]
$$

therefore

$$
\frac{\mathrm{d} A}{\mathrm{~d} t}+h A=h k C_{\mathrm{m}}\left(1-\mathrm{e}^{-h^{\prime} t}\right)
$$

Integration and imposition of the condition $A=0$ when $t=0$ yields

$$
A=\frac{k C_{\mathrm{m}}}{\left(h-h^{\prime}\right)}\left[h\left(1-\mathrm{e}^{-h^{\prime} t}\right)-h^{\prime}\left(1-\mathrm{e}^{-h t}\right)\right] \ldots
$$

as the system response to the exponential concentration - time input. If the volume of the real tank is large then, $h^{\prime} \rightarrow 0$ so that the response approximates to that for a single tank [equation (10)]

\section{Flow injection}

In FI-AAS, other conditions being constant, the peak signal $A_{\mathrm{p}}$ is always less than the steady-state signal $A_{\mathrm{m}}$ owing to real dispersion in the manifold and apparent dispersion due to the detector. In the absence of any manifold dispersion, the peak absorbance is given by equation (17). The time to reach the peak is $t_{\mathrm{p}}=V_{\mathrm{i}} / u$, thus

$$
A_{\mathrm{p}}=A_{\mathrm{m}}\left(1-\mathrm{e}^{-V_{\mathrm{i}} / V}\right) \ldots
$$

From this equation, the volume injected $\left(V_{\mathrm{i}}\right)_{99}$ to produce a peak signal equal to $99 \%$ of the steady-state absorbance, $\left(V_{\mathrm{i}}\right)_{99}$, is calculated to be $V \ln (100)$.

For a typical value of $V$ for the instrument used in these studies $(40 \mu \mathrm{l})$ the value of $\left(V_{\mathrm{i}}\right)_{99}$ is $180 \mu \mathrm{l}$, i.e., a volume of at least $180 \mu \mathrm{l}$ must be injected to produce an $A_{\mathrm{p}}$ value equal to $99 \%$ of $A_{\mathrm{m}}$. If volumes of less than $180 \mu \mathrm{l}$ are injected, then, the recorded peak would be reduced, due to the failure to attain the steady-state response. The injection of small sample volumes will give rise to high apparent dispersion coefficients due solely to detector response characteristics. By way of example, a 5- $\mu$ l sample injected close to the nebuliser would yield a peak measuring about $12 \%$ of $A_{\mathrm{m}}$, i.e., showing an "apparent" or "detector" dispersion coefficient of 8 . Despite this, FI-AAS is a valid technique because, for a fixed injection volume, a constant fraction, $\left(1-\mathrm{e}^{-V_{\mathrm{i}} / V}\right)$, of the pulse is recorded, and this remains proportional to the sample concentration, as explained in the discussion of discrete nebulisation.

\section{Defects of the single-tank model}

Equation (20) predicts that $A_{\mathrm{p}}$ is independent of the sample fow-rate $u$. In practice this is not so, thus, although the singletank model accounts for the effects of varying sample volume and concentration, it does not predict the results of changing flow-rate. Before describing the further refinement of the model, a brief account of the contributions of other workers towards rationalising the complexities of pneumatic nebulisation is presented.

\section{Pneumatic Nebuliser}

A recent report by Browner and Boorn ${ }^{27}$ has emphasised the current interest in nebuliser studies as a possible means of improving instrument performance. The nebulisation process is illustrated in Fig. 3. Air at a pressure $P_{1}$, maintained by a suitable compressor, is allowed to escape via a venturi nozzle $\mathrm{N}$. As the gas accelerates towards sonic velocity at the venturi throat, its pressure falls isentropically (adiabatically and reversibly) to a value $P_{2}$ in accordance with Bernoulli's principle. Beyond the throat, the airstream broadens, its velocity falls and kinetic energy is transformed into potential energy, compressing the air to a pressure $P_{3}$, close to atmospheric pressure. Mathematical treatments of these processes are given in standard texts of fluid mechanics. 33,34

By comparison, the mechanism of aerosol formation is not 


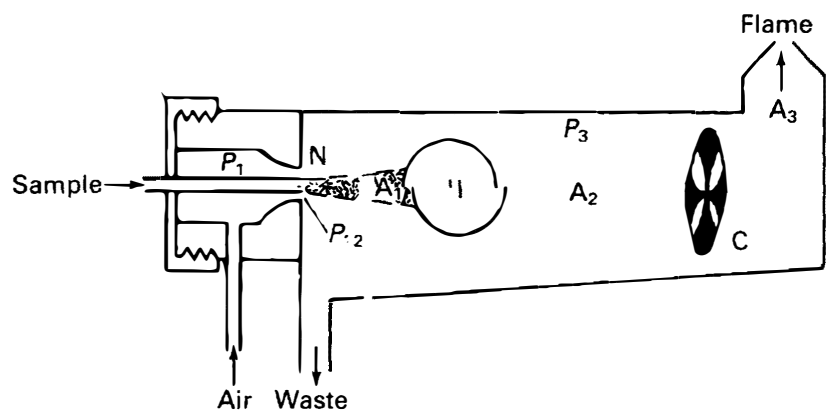

Fig. 3. Basic mode of action of the concentric pneumatic nebuliser. $\mathrm{N}$ is a venturi nozzle, I an impact bead and $\mathrm{C}$ a centrifugal spoiler. For detailed explanation see text

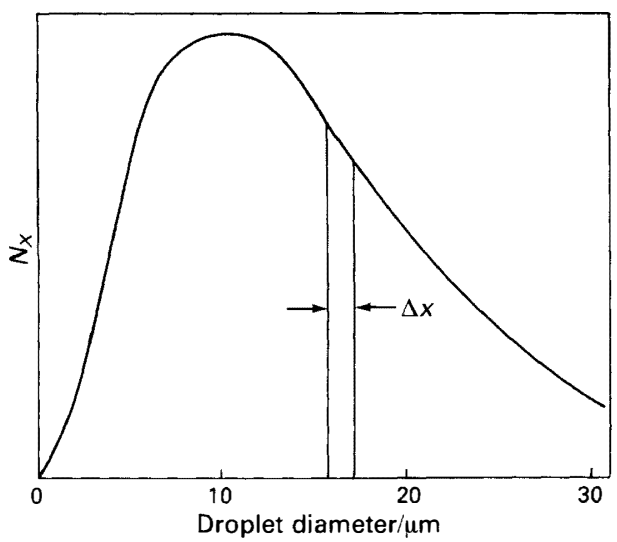

Fig. 4. Droplet size distribution according to the Nukiyama and Tanasawa equation. $N_{x}$ is the number of droplets with diameters between $(x-\triangle x / 2)$ and $(x+\triangle x / 2)$. When $Q_{\mathrm{g}} / Q_{1}>5000$ and $V_{\mathrm{g}}>$ $180 \mathrm{~m} \mathrm{~s}^{-1}, p$ and $q$ are reported to be 2 and 1 , respectively. The values of $A$ and $B$ are 0.9 and 0.2 , respectively

well understood and no exact theoretical treatment is available. One can only be guided by the results of various empirical investigations and the theoretical explanations that have been proposed. In a typical concentric nebuliser, $P_{2}$ is below atmospheric pressure, so that sample is aspirated into the air stream through the nebuliser capillary, whose tip is axially positioned in the venturi tube. The resultant diverging jet of primary aerosol $A_{1}$ strikes the impact bead I and shatters to yield a secondary aerosol $A_{2}$, which progresses through a centrifugal spoiler (not present in all commercial designs) before entering the flame as the tertiary aerosol $\mathrm{A}_{3}$.

As fine droplets improve instrument sensitivity and linearity of response whilst reducing interference effects ${ }^{19,27}$ the supreme purpose of the nebuliser assembly is to introduce into the flame a large mass of sample in the finest possible form. Much effort has been directed towards attaining this goal, both in nebuliser design and in aerosol research. ${ }^{25,27}$

Despite the extent of the work, understanding of the processes involved is still rather limited. Many sources ${ }^{17,26,27,35}$ quote the empirical equations of Nukiyama and Tanasawa [equations $(21 a$ and $b)$ ] as a starting point in describing primary aerosol formation in concentric nebulisers.

The distribution of droplets may be described by an equation of the form (see Fig. 4)

$$
N_{x}=A x^{p} \exp \left(-B x^{q}\right)
$$

where $x$ is droplet diameter and $A, B, p$ and $q$, are constants and $N_{x}$ is the number of droplets with diameter between $(x-\Delta x / 2)$ and $(x+\Delta x / 2)$.

The Sauter mean diameter of the droplets (diameter of droplet whose volume to surface area ratio is the mean of the distribution) is given by $x_{0}$ where
$x_{0}=\frac{585}{\left(V_{\mathrm{g}}-V_{1}\right)}\left(-\frac{\sigma}{\rho}\right)^{0.5}+597\left[\frac{\eta}{(\sigma \rho)^{0.5}}\right]^{0.45}\left(\frac{1000 Q_{1}}{Q_{\mathrm{g}}}\right)^{1.5}$

where $\sigma$ is surface tension (dyn $\left.\mathrm{cm}^{-1}\right), \rho$ is liquid density $\left(\mathrm{g} \mathrm{ml}^{-1}\right), \eta$ is liquid viscosity [poise $\left.(\mathrm{p})\right], V_{1}$ and $V_{\mathrm{g}}$ are the linear velocities of liquid and gas flows $\left(\mathrm{m} \mathrm{s}^{-1}\right)$, respectively, and $Q_{1}$ and $Q_{\mathrm{g}}$ are the volumetric flow-rates of liquid and gas, respectively $\left(\mathrm{ml} \mathrm{s}^{-1}\right)$. These useful equations ${ }^{26}$ are based on several hundred tests under different conditions using subsonic gas flows. ${ }^{35}$ Bitron $^{16}$ has shown that equation (21b) applies equally well to supersonic flow. However, it should be noted that the equation is dimensionally inconsistent and is also said to predict too high a proportion of large droplets. ${ }^{15}$ Its value, nevertheless, unlike the proposed mathematical alternatives, is that its parameters are readily identified with the operational variables of nebuliser systems.

Equation (21a) indicates a wide range of droplet diameters in the primary aerosol (see Fig. 4) whilst (21b) implies that the mean droplet diameter is reduced by employing high volumetric gas flow at high throat velocity, and low volumetric liquid flow emerging at high linear velocity, i.e., a fine nebuliser capillary is best.

These results are supported by the findings of Lane ${ }^{14}$ who investigated the critical velocity at which droplets shattered in air. He found

$$
d=\frac{612}{(v-u)^{2}}
$$

where $d$ is the droplet diameter in $\mathrm{mm}, v$ is the critical air velocity and $u$ is the droplet velocity on bursting in $\mathrm{m} \mathrm{s}^{-1}$. Thus, increasing $u$ stabilises larger droplets, whilst increasing $v$ destabilises larger droplets in favour of smaller ones.

Cresser ${ }^{25}$ has observed that increased volumetric flow of liquid increases the pressure $P_{2}$ at the capillary tip. It might be envisaged that increased liquid flow results in loss of kinetic energy of the air stream due to collision with an increasing mass of liquid, which in turn removes the seat of the pressure depression. At high liquid flow-rates the mass flow of liquid (5-10 $\left.\mathrm{ml} \mathrm{min}^{-1}\right)$ may approach that of the gas $\left(81 \mathrm{~min}^{-1}\right)$. As aerosol production and transport are powered by the energy of the air stream, it is likely that these processes will be influenced by liquid flow-rate. However, the bulk of the energy expended in forming droplets and accelerating them to the speed of the air stream is redistributed as thermal energy as $c a .95 \%$ of the aerosol mass strikes the walls of the spray chamber and drains to waste. Evaporation of water from the droplets and from the walls of the spray chamber constitutes the main loss of energy carried by the air stream. ${ }^{18}$

A typical Sauter mean droplet diameter may be calculated using data for distilled water at $20{ }^{\circ} \mathrm{C}$ namely $\sigma=72.6$ dyn $\mathrm{cm}^{-1}, \rho=0.998 \mathrm{~g} \mathrm{ml}^{-1}$ and $\eta=0.010 \mathrm{p}$. Substituting these values in equation $(21 b)$ yields

$$
x_{0}=\left(\frac{4990}{V_{\mathrm{g}}-V_{1}}\right)+28.7\left(\frac{1000 Q_{\mathrm{l}}}{Q_{\mathrm{g}}}\right)^{1.5}
$$

For a typical nebuliser, $V_{1}=1 \mathrm{~m} \mathrm{~s}^{-1}$, therefore

$$
\begin{gathered}
V_{\mathrm{g}}-V_{\mathrm{l}} \simeq V_{\mathrm{g}}=330 \mathrm{~m} \mathrm{~s}^{-1} \\
1000 \times \frac{Q_{\mathrm{l}}=1000 \times 8 \mathrm{ml} \mathrm{min}^{-1}}{Q_{\mathrm{g}}}=\frac{81 \mathrm{~min}^{-1}}{10}=1 \\
x_{0}=\frac{4990}{\underline{330}}+28.7=15.0+28.7=43.7 \mu \mathrm{m}
\end{gathered}
$$

i.e., the mean droplet diameter of the primary aerosol is 43.7 $\mu \mathrm{m}$. Three sets of results calculated in this way are illustrated in Fig. 5.

After investigating the effect of nebuliser geometry under fixed operating conditions, Hrubecky ${ }^{17}$ confirmed that maximum nebulisation occurs when the liquid is injected along the central axis of the air stream at the point of maximum velocity. 


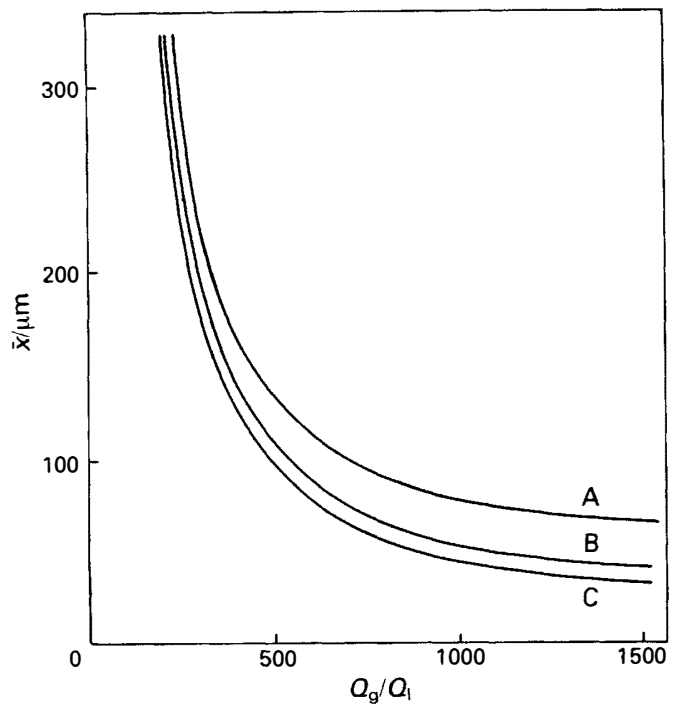

Fig. 5. Mean droplet diameter as a function of $Q_{\mathrm{g}} / Q_{1}$. The values of $V_{\mathrm{g}}-V_{1}$ are: A, 100; B, 200; and C, $300 \mathrm{~m} \mathrm{~s}^{-1}$

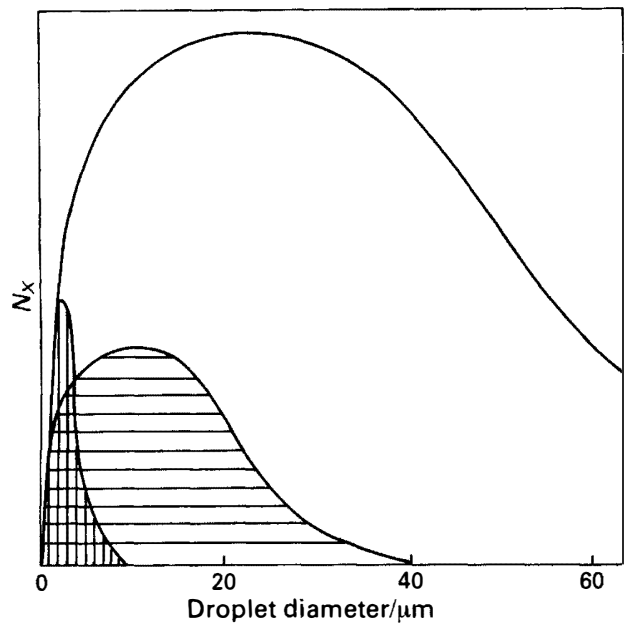

Fig. 6. Approximate relative distributions of droplets in primary (horizontal shading), secondary and tertiary (vertical shading) aerosols of a typical AAS nebuliser

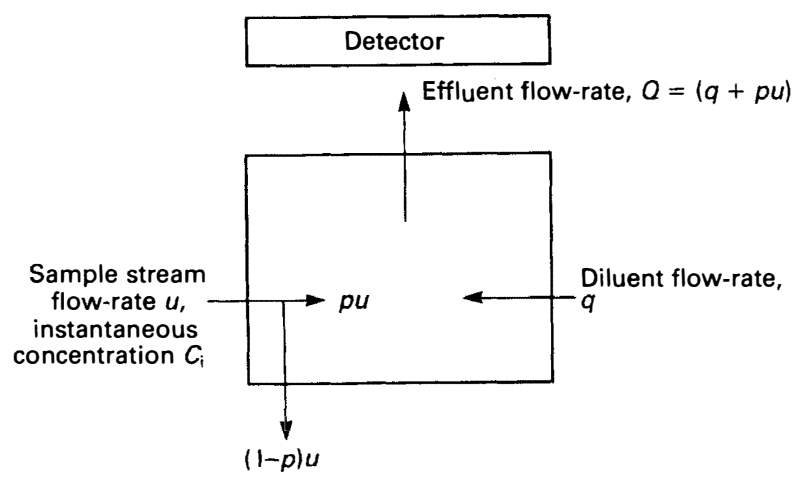

Fig. 7. Basis of the extended-tank model

In this way, the maximum area of liquid surface comes in contact with the air stream with little disturbance of the flow to impair the formation of ligaments/droplets at the surface, after the mechanism proposed by Castleman. ${ }^{12}$

Impactor surfaces, placed in the path of the primary aerosol jet, are widely employed to increase the volume of aerosol generated. Experimental evidence indicates that they also raise the mean diameter of the droplet distribution. ${ }^{21}$ Formation of larger droplets might result from fragmentation of the liquid film deposited on the surface of the bead ${ }^{25}$ and from disruption of the airstream both by the bead and by the shattering of the primary liquid droplets. ${ }^{17}$ Thus the immediate result is probably an increased volume of secondary aerosol of inferior quality. Fortunately, many of the larger droplets are short-lived, as the great bulk are removed by gravitation and by collision with the walls of the spray chamber, a process promoted by such devices as centrifugal spoilers, so that the tertiary aerosol that finally enters the flame is much finer. These modifications of the aerosol, from generation to entry into the flame, are illustrated in Fig. 6.

In view of the complexity of the nebulisation process, the probability of deriving theoretical expressions linking absorbance and nebulisation rate appears remote. Clearly $u, Q_{1}$ and $Q_{\mathrm{g}}$ contribute to the character of the aerosol entering the flame, which in turn determines the absorbance signal, but, apart from qualitative guidelines, little more can be said to link these entities.

Under these circumstances, a possible solution is to attempt to extend the single-tank model to take account of the effects of flow-rate.

\section{Extension of the Single-tank Model to Accommodate the Effects of Flow-rate}

The single-tank model was extended as shown in Fig. 7. The well-stirred hypothetical tank of volume $V$ has two inputs: a constant stream of diluent, flow-rate $q$, and sample stream, flow-rate $u$. A useful fraction, $p$, of the sample is dispersed throughout the tank whilst the remainder flows to waste. The observed system response is proportional to concentration and rate of introduction to the detector. Incompressible flow is assumed throughout and $p$ is a function of flow-rate. Consideration of the analyte mass balance of the tank yields

$$
\left(\frac{\mathrm{d} m}{\mathrm{~d} t}\right)_{\mathrm{tank}}=\left(\frac{\mathrm{d} m}{\mathrm{~d} t}\right)_{\text {in }}-\left(\frac{\mathrm{d} m}{\mathrm{~d} t}\right)_{\text {out }}=p u C_{\mathrm{i}}-Q C
$$

Division by $V$ yields

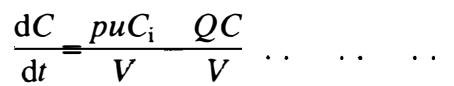

The model for the detector response is that the absorbance is proportional to the rate at which analyte enters the detector, i.e., $A=k Q C$. Substitution for $Q C$ in equation (22a) yields

$$
\frac{V}{Q} \frac{\mathrm{d} A}{\mathrm{~d} t}+A=k p u C_{\mathrm{i}} \quad \ldots \quad \ldots
$$

Equations (22a and $b$ ) are mathematical expressions of the extended-tank model of the system response.

\section{Examination of the Extended-tank Model}

An acceptable model must account for the experimentally observed responses of the system.

System response to a step change in concentration from zero to $\mathrm{C}_{m}$ at a steady flow-rate $\mathrm{u}$

Substitution of $C_{\mathrm{i}}=C_{\mathrm{m}}$ into equation (22a) yields

$$
\frac{\mathrm{d} C}{\mathrm{~d} t}+\frac{Q C}{V}=\frac{p u C_{\mathrm{m}}}{V}
$$

Integration and writing $C=0$ when $t=0$ gives the solution

$$
C=\frac{p u}{Q} C_{\mathrm{m}}\left(1-\mathrm{e}^{-Q t / V}\right) \quad \ldots \quad \ldots
$$

and

$$
A=k p u C_{\mathrm{m}}\left(1-\mathrm{e}^{-Q t / V}\right) \quad \ldots \quad \ldots
$$

i.e., the model predicts the exponential growth of absorbance to a steady-state value $A_{\mathrm{m}}$ equal to $k p u C_{\mathrm{m}}$, the system 
response time constant being determined by the total flow $Q$ through the system, rather than by the sample flow $u$. Thus, more rapid response is predicted by increasing the diluent flow, $q$. The greater dilution of the sample is compensated by increased volume flow-rate to the ideal detector so that absorbance is unaffected if $p$ remains constant.

At first sight, it might be thought possible to equate $p$ in the model with the transport efficiency of the real nebuliser, but that would be gross oversimplification as there is an empirical function relating absorbance and sample flow-rate for a given set of operating conditions. In a real system, absorbance depends on a number of interconnected variables. It is not possible to vary sample flow-rate whilst all the others remain constant (e.g., nebulisation efficiency changes with flow-rate). Browner et al. ${ }^{28}$ have developed the concept of useful aerosol mass $\left(W_{u}\right)$ as a single figure of merit for nebuliser performance. Whilst useful in nebuliser studies and in development work, the concept is of limited operational application as it is not readily evaluated in terms of the experimental variables. In FI-AAS work, interest centres around the useful exploitation of flow-rate while all other operating parameters remain fixed. The model parameter $p$ may find application in this context. It is emphasised, however, that $p$, like $W_{u}$, is a complex function of over-all nebuliser performance, and which, even for a single system, probably does not have day to day reproducibility. Nevertheless, it does represent a convenient means of making quantitative allowance for nebulisation effects within a physical model, which otherwise totally ingores that problem area, the aerosol.

Results obtained using real AA detectors reveal that the gradient of the graph of absorbance against flow-rate decreases with increasing flow-rate, eventually becoming zero or negative under the influence of such factors as lower nebuliser efficiency, changes in droplet size distribution and increased solvent loading to the flame. These effects would be modelled using a $p$-function that decreases with sample flow-rate. It is hoped that a further study of the way in which $p$ varies might provide information useful in optimising the system.

\section{FI-AAS predictions}

Assuming no manifold dispersion (i.e., plug flow), the response predicted by the extended-tank model to a step change from 0 to $C_{\mathrm{m}}$ is given by equation $(23 b)$. If a discrete volume $V_{\mathrm{i}}$ is injected at a constant flow-rate $u$, then $t_{\mathrm{p}}=V_{\mathrm{i}} / u$ and

$$
A_{\mathrm{p}}=k p u C_{\mathrm{m}}\left(1-\mathrm{e}^{-Q V_{\mathrm{i}} / u V}\right) \quad \ldots
$$

When $u$ and $V_{\mathrm{i}}$ are constant, equation (24) simplifies to $A_{\mathrm{p}}$ $\propto C_{\mathrm{m}}$, i.e., peak height is a valid measure of injected concentration.

When $C_{\mathrm{i}}$ and $V_{\mathrm{i}}$ are constant, then $A_{\mathrm{p}}$ varies with $u$ according to the equation

$$
A_{\mathrm{p}}=A_{\mathrm{m}}\left(1-\mathrm{e}^{-Q V_{\mathrm{i}} / u V}\right) \quad \ldots \quad \ldots
$$

Thus the peak height varies with flow-rate in a similar manner to the steady-state value. Note however that both the steady-state maximum $A_{\mathrm{m}}$ and the fraction recorded as the pulse $A_{\mathrm{p}}$ are functions of flow-rate, so that the response dispersion coefficient, too, varies with flow-rate, i.e., from equation (25),

$$
D_{\mathrm{r}}=\frac{A_{\mathrm{m}}}{A_{\mathrm{p}}}=\left(1-\mathrm{e}^{\left.-Q V_{\mathrm{i}} / u V\right)^{-1}} \ldots \ldots\right.
$$

As $u$ and $C_{\mathrm{m}}$ are constant, equation (25) predicts that $A_{\mathrm{p}}$ increases exponentially with $V_{\mathrm{i}}$ up to a maximum of $A_{\mathrm{m}}$ when $V_{\mathrm{i}}=\infty$.

Experiments (see later) show that $A_{\mathrm{p}}$ passes through a maximum value $\left(A_{\mathrm{p}}\right)_{\max }$. with increasing $u$, and thereafter decreases. Substituting $Q=q+p u$ into equation (24), followed by differentiation with respect to $u$ and setting $\mathrm{d}\left(A_{\mathrm{p}}\right) / \mathrm{d} u=0$ yields the equation

$$
\left(\mathrm{e}^{Q V_{\mathrm{i}} / u V}-1\right)\left(p+u \frac{\mathrm{d} p}{\mathrm{~d} u}\right)=p u V_{\mathrm{i}}\left(\frac{\mathrm{d} p}{\mathrm{~d} u}-\frac{q}{u^{2}}\right) \ldots
$$

If the function $p$ is known in terms of $u$, equation (27) may be solved to give a value for $u_{\text {max }}$, the sample flow-rate giving maximum FI-AAS response using an injected volume $V_{\mathrm{i}}$.

\section{Peak-width measurements}

When the single-tank model was adopted in preference to the parallel-tanks model, it was accepted that observations should be limited to the initial part of the absorbance - time response graph which approximates to a simple exponential function. Thus it is expected that the single-tank model will lose its quantitative validity as observation times are extended up towards steady-state conditions. This limitation should be borne in mind when considering measurements of peak width. Some error might appear inevitable, nor can it be minimised by measuring close to the base line, because although this corresponds to a short observation time for the growth graph, it represents a long observation time for the decay graph. It may be that the best accuracy is achieved by measuring at half the peak height, as is done in chromatography, as it has been shown (see later) that the initial part of the response graph approximates closely to a single exponential function.

Tyson ${ }^{36}$ has used peak-width measurement at a constant height above the base line as a means of extending the calibration range of an atomic absorption spectrometer over several orders of magnitude. Signal growth is described by equation $(23 b)$, which may be rearranged to give

$$
t=\frac{V}{Q} \ln \left(\frac{A_{\mathrm{m}}}{A_{\mathrm{m}}-A}\right) \quad \ldots \quad \ldots
$$

Whilst for the corresponding signal decay, the time measured from the peak maximum is given by

$$
t=\frac{V}{Q} \ln \left(\frac{A_{\mathrm{p}}}{A}\right) \quad \ldots \quad \ldots \quad \ldots
$$

Fig. 8 shows that the total peak width at the absorbance level $A_{1}$ is given by $t^{\prime}$ where $t^{\prime}=t_{\mathrm{p}}-t_{1}+t_{2}$

Substituting the appropriate expressions from equations (28) and (29) yields the equation

$$
t^{\prime}=\frac{V_{\mathrm{i}}}{u}-\frac{V}{Q} \ln \left(\frac{A_{\mathrm{m}}}{A_{\mathrm{m}}-A_{1}}\right)+\frac{V}{Q} \ln \left(\frac{A_{\mathrm{p}}}{A_{1}}\right)
$$

Substituting from equation (26) and rearranging gives

$$
t^{\prime}=\frac{V}{Q} \ln \left(\frac{A_{\mathrm{m}}-A_{1}}{A_{1}}\right)\left(\frac{1}{D_{\mathrm{r}}-1}\right) \quad \ldots
$$

At constant flow-rate both $Q$ and $D_{\mathrm{r}}$ are constant and absorbance is proportional to the concentration of analyte in the hypothetical tank, so that equation (30) reduces to the form

$$
t^{\prime}=m \ln \left(C_{\mathrm{m}}-C_{1}\right)+c \quad \ldots \quad \ldots
$$

i.e., a plot of peak width against $\ln \left(C_{\mathrm{m}}-C_{1}\right)$ is a straight line of gradient $V / Q$. Substitution for $A_{\mathrm{m}}$ and $D_{\mathrm{r}}$ in equation (30) yields the following expression for the variation of peak width with flow-rate.

$$
t^{\prime}=\ln \left[\left(\mathrm{e}^{Q V_{\mathrm{i}} / u V}-1\right)\left(\frac{k p u C_{\mathrm{i}}}{A_{1}}-1\right)\right] \ldots
$$

Peak width-at constant height is therefore dependent upon both injected concentration and flow-rate.

If peak width is measured at a constant fraction of peak height, $A_{\mathrm{p}} / n$, then

$$
\frac{A_{\mathrm{m}}}{A_{1}}=\frac{n A_{\mathrm{m}}}{A_{\mathrm{p}}}=n D_{\mathrm{r}}
$$




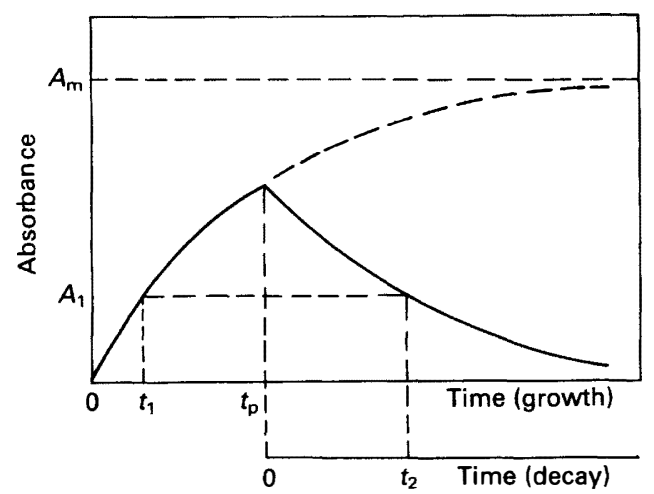

Fig. 8. Basis for the derivation of an expression for peak width from the extended-tank model

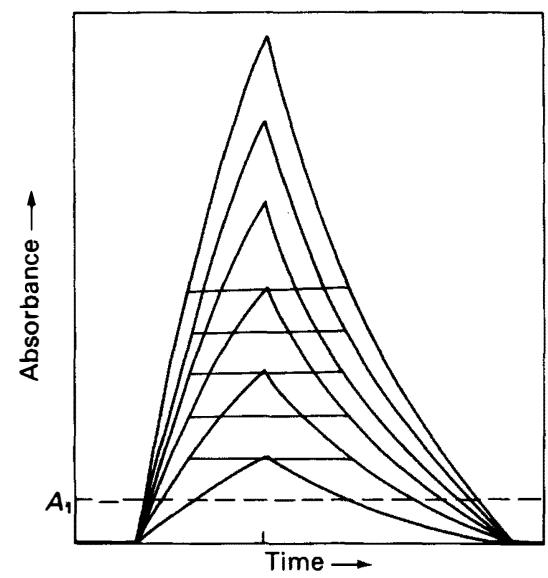

Fig. 9. Effect of increasing $C_{\mathrm{i}}$ on peak width ( $V_{\mathrm{i}}$ is constant). The peak width at half maximum height remains constant and the width at constant height increases

Substituting this value of $A_{\mathrm{m}} / A_{1}$ into equation (30) yields the equation

$$
t_{n}^{\prime}=\frac{V}{Q} \ln \left(\frac{n D_{\mathrm{r}}-1}{D_{\mathrm{r}}-1}\right)
$$

Thus, in contrast with the last result, the peak width at a constant fraction of peak height is independent of the injected concentration.

Substitution from equation (26) yields the equation

$$
t_{n}^{\prime}=\frac{V}{Q} \ln \left[(n-1) \mathrm{e}^{Q} Q V_{\mathrm{i}} / V u+1\right] \ldots
$$

If the peak width is measured at half the peak height then $n=$ 2 and

$$
t^{\prime}{ }_{2}=\frac{V}{Q} \ln \left(\mathrm{e}^{Q V_{\mathrm{i}} / V u}+1\right) \quad \ldots \quad \ldots
$$

This is illustrated in Fig. 9.

\section{Experimental}

\section{Apparatus}

The following apparatus was used: Shandon Southern A3400 atomic absorption spectrometer, Tekmann TE200 chart recorder, Gilson Minipuls 2 peristaltic pump, Rheodyne Model RH5031 3-way PTFE rotary valve, Altex Model 201-25 eight-port injection valve and Marriott bottles (constant-head reservoirs).

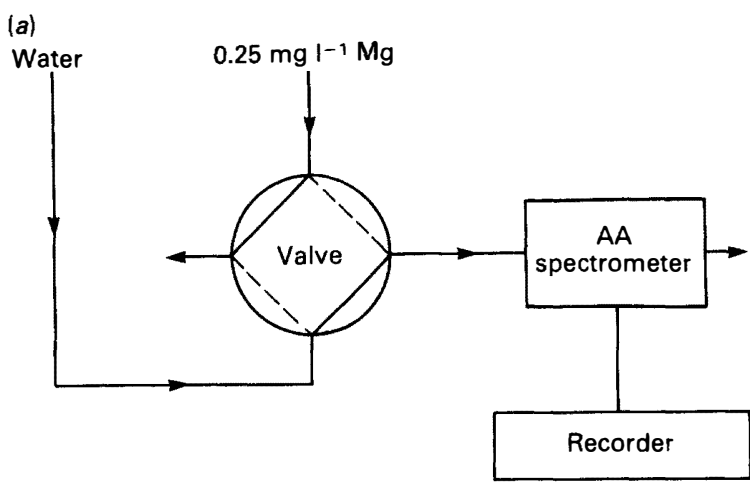

(b)

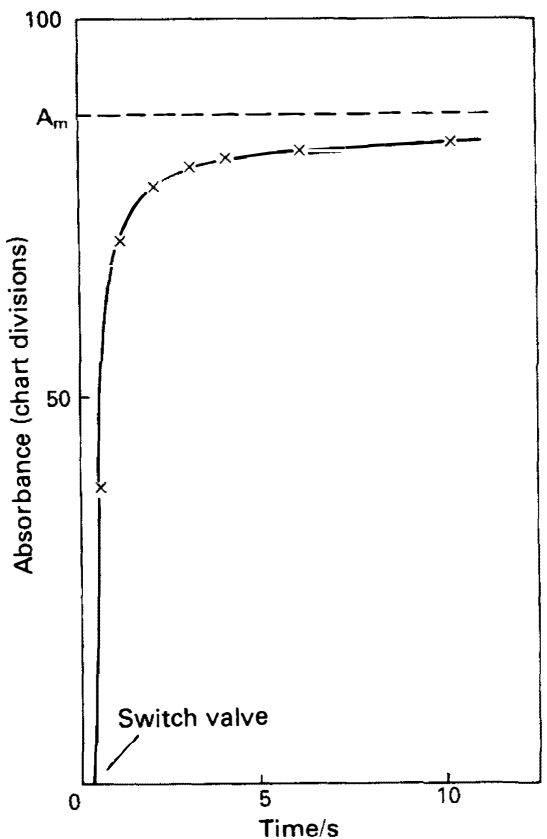

Fig. 10. (a) Experimental set-up and (b) results for study of absorbance versus time for a step change in concentration from 0 to $0.25 \mathrm{mg} \mathrm{1}^{-1}$ of magnesium

\section{Standard Solution}

A $1000 \mathrm{mg} \mathrm{l}^{-1}$ solution of magnesium (BDH Chemicals Ltd.) was used.

\section{Procedures}

Investigation of single-tank model of system response

Marriott bottles containing triply distilled water and 0.25 $\mathrm{mg} \mathrm{l}^{-1}$ magnesium solution were connected to alternate inlets of the three-way valve. The common outlet was connected directly to the nebuliser by means of a $4.5 \mathrm{~cm}$ length of 0.58 $\mathrm{mm}$ i.d. PTFE tube (Fig. 10). No pump was employed. Switching the valve smartly changed the input from water to magnesium solution. The growth of absorbance with time was monitored by the chart recorder operating at its maximum speed of $1 \mathrm{~cm} \mathrm{~s}^{-1}$. The procedure was repeated four times and the five sets of results were pooled to obtain the mean absorbance - time growth profile. The solution flow-rate was determined by measuring the time taken for the aspiration of $20 \mathrm{ml}$ of solution, delivered by pipette to the intake of the appropriate supply line without changing the hydrostatic head.

\section{Effect of flow-rate on instrument response}

A $0.5 \mathrm{mg} \mathrm{l}^{-1}$ magnesium solution was used as the test sample as the AA sensitivity for magnesium is high $\left(0.5 \mathrm{mg} \mathrm{l}^{-1}\right.$ gives 
Table 2. Variation of $A_{\mathrm{m}} / A_{\mathrm{p}}$ with volume injected and flow-rate

\begin{tabular}{rccccccccc} 
& & \multicolumn{8}{c}{$u / \mathrm{ml} \mathrm{min}^{-1}$} \\
$V_{\mathrm{i} /} / \mu \mathrm{l}$ & 1 & 2 & 3 & 4 & 5 & 6 & 7 & 8 & 9 \\
30 & 1.90 & 2.13 & 2.29 & 2.54 & 2.80 & 3.08 & 3.39 & 3.69 & 3.91 \\
70 & 1.29 & 1.29 & 1.42 & 1.54 & 1.67 & 1.79 & 1.92 & 2.03 & 2.13 \\
100 & 1.16 & 1.15 & 1.21 & 1.29 & 1.38 & 1.46 & 1.54 & 1.61 & 1.62 \\
150 & 1.03 & 1.05 & 1.07 & 1.11 & 1.17 & 1.23 & 1.28 & 1.30 & 1.31 \\
\hline
\end{tabular}

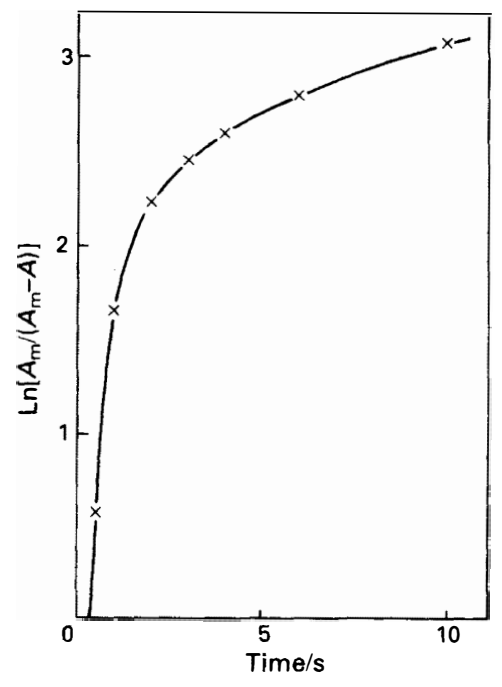

Fig. 11. Plot of $\ln \left[A_{\mathrm{m}} /\left(A_{\mathrm{m}}-A\right)\right]$ versus $t$ for results shown in Fig. 10

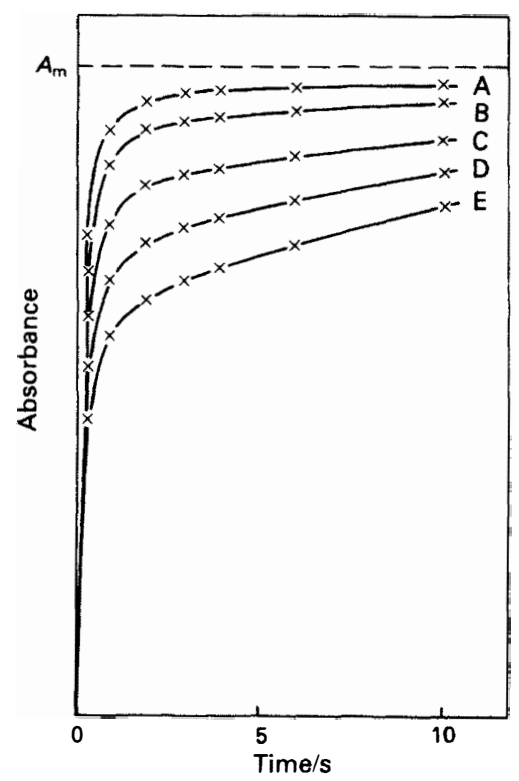

Fig. 12. Computer generated curves on the basis of the paralleltanks model for different values of $f_{1}: \mathrm{A}, 0.95 ; \mathrm{B}, 0.9 ; \mathrm{C}, 0.8 ; \mathrm{D}, 0.7$ and $\mathrm{E}, 0.6$. The values of $u, V_{1}$ and $V_{2}$ are $0.127 \mathrm{ml} \mathrm{s}^{-1}, 0.044 f_{1}$ and $1.98\left(1-f_{1}\right)$, respectively

0.44 absorbance) and the calibration graph shows no significant curvature over the concentration range $0-0.5 \mathrm{mg} \mathrm{l}^{-1}$. Using the Altex valve, $30 \mu \mathrm{l}$ of the magnesium solution were placed in a flowing stream of distilled water immediately before it entered the nebuliser. Triplicate peaks were recorded at various pumping rates over the range 1-9 $\mathrm{ml} \mathrm{min}^{-1}$. The procedure was repeated for $70-, 100-$ and $150-\mu \mathrm{l}$ injections. The corresponding steady-state signals $\left(V_{\mathrm{i}}=\infty\right)$ were

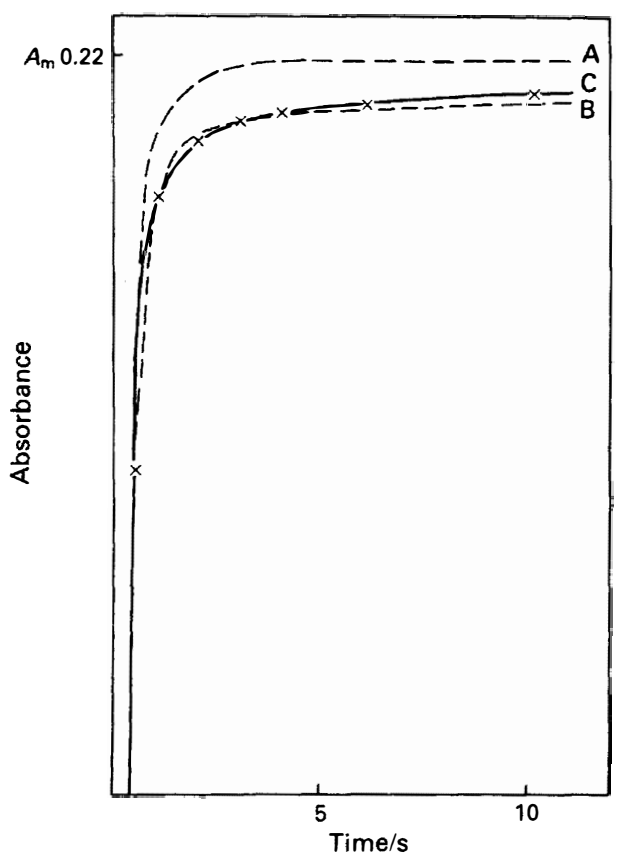

Fig. 13. Comparison of single- and parallel-tanks models of the absorbance - time function for a step concentration change from zero to $0.5 \mathrm{mg} \mathrm{l}^{-1} \mathrm{Mg}$. A, Best fit for single-tank model; B, best fit for parallel-tanks model; and C, experimental curve

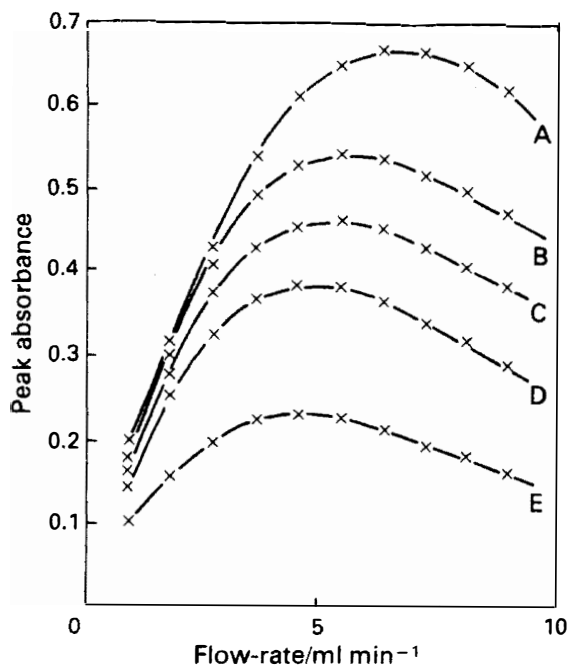

Fig. 14. Effect of flow-rate on steady-state absorbance and on peak absorbance for the injection of a variety of sample volumes. A, Steady state; B, 150; C, 100; D, 70; and E, $30 \mu \mathrm{l}$

obtained by pumping a continuous stream of $0.5 \mathrm{mg}^{-1}$ magnesium solution to the nebuliser at the same flow-rates and noting the absorbance values. In order to minimise manifold dispersion, the injection valve and nebuliser were connected by a short length $(4.5 \mathrm{~cm})$ of $0.58 \mathrm{~mm}$ i.d. PTFE tubing. The performance of the pump was checked by 
Table 3. Variation of peak absorbance with flow-rate and volume injected

\begin{tabular}{|c|c|c|c|c|c|c|c|}
\hline \multirow{3}{*}{$\begin{array}{c}\text { Flow- } \\
\text { rate } \\
(u) / \\
\mathrm{ml} \mathrm{min}^{-1}\end{array}$} & \multicolumn{5}{|c|}{ Injected volume $(V) / \mu l$} & \multirow{3}{*}{$\begin{array}{c}Q / V \\
\text { value } \\
\text { indicated }\end{array}$} & \multirow{3}{*}{$\begin{array}{l}\text { Pearson } \\
\text { correlation } \\
\text { coefficient }\end{array}$} \\
\hline & 30 & 70 & 100 & 150 & $\infty$ & & \\
\hline & \multicolumn{5}{|c|}{ Peak absorbance $\left(A_{\mathrm{p}}\right)$} & & \\
\hline 1 & 0.105 & 0.155 & 0.172 & 0.195 & 0.200 & 0.396 & 0.996 \\
\hline 2 & 0.158 & 0.260 & 0.293 & 0.320 & 0.336 & 0.824 & 1.000 \\
\hline 3 & 0.204 & 0.330 & 0.385 & 0.435 & 0.467 & 0.846 & 0.999 \\
\hline 4 & 0.224 & 0.369 & 0.440 & 0.512 & 0.567 & 1.01 & 0.999 \\
\hline 5 & 0.226 & 0.379 & 0.457 & 0.537 & 0.632 & 1.01 & 1.000 \\
\hline 6 & 0.214 & 0.369 & 0.452 & 0.535 & 0.660 & 1.06 & 1.000 \\
\hline 7 & 0.196 & 0.346 & 0.431 & 0.518 & 0.665 & 1.13 & 1.000 \\
\hline 8 & 0.176 & 0.317 & 0.404 & 0.496 & 0.649 & 1.26 & 1.000 \\
\hline 9 & 0.157 & 0.288 & 0.380 & 0.467 & 0.614 & 1.43 & 0.999 \\
\hline
\end{tabular}

Table 4. Values of extended-model parameters $V, b$ and $q$

\begin{tabular}{|c|c|c|c|c|c|c|c|}
\hline \multirow{3}{*}{$\begin{array}{l}\text { Volume } \\
\left(V_{\mathrm{i}}\right) / \mu \mathrm{l}\end{array}$} & \multirow{2}{*}{\multicolumn{3}{|c|}{$\begin{array}{l}\text { Least-squares fit to } \\
y=A+B u+C u^{2}\end{array}$}} & \multirow{3}{*}{$\begin{array}{c}\text { Pearson } \\
\text { correla- } \\
\text { tion } \\
\text { coeffi- } \\
\text { cient }\end{array}$} & \multicolumn{3}{|c|}{$\begin{array}{l}\text { Values implied } \\
\text { for model }\end{array}$} \\
\hline & & & & & \multirow{2}{*}{$\begin{array}{l}V / \\
\mu l\end{array}$} & \multirow{2}{*}{$\begin{array}{c}b / \\
\mathrm{s} \mathrm{ml}^{-1}\end{array}$} & \multirow{2}{*}{$\begin{array}{c}q / \\
\mu \mathrm{l} \mathrm{s}^{-1}\end{array}$} \\
\hline & $A$ & $B$ & $C$ & & & & \\
\hline 30 & 0.433 & $12.1 \%$ & -35.38 & 0.996 & 82 & & 35.6 \\
\hline 70 & & 12.5 & -39 & 0.9 & 80 & & 26.9 \\
\hline 100 & & 11.05 & -28 & 0.9 & 90 & 2. & 33.6 \\
\hline \multirow[t]{2}{*}{150} & 0.3488 & 11.13 & -29 . & 0.966 & 90 & 2. & 31.3 \\
\hline & \multicolumn{3}{|c|}{ Mean values } & . . . & 85.5 & 2.8 & 31.9 \\
\hline
\end{tabular}

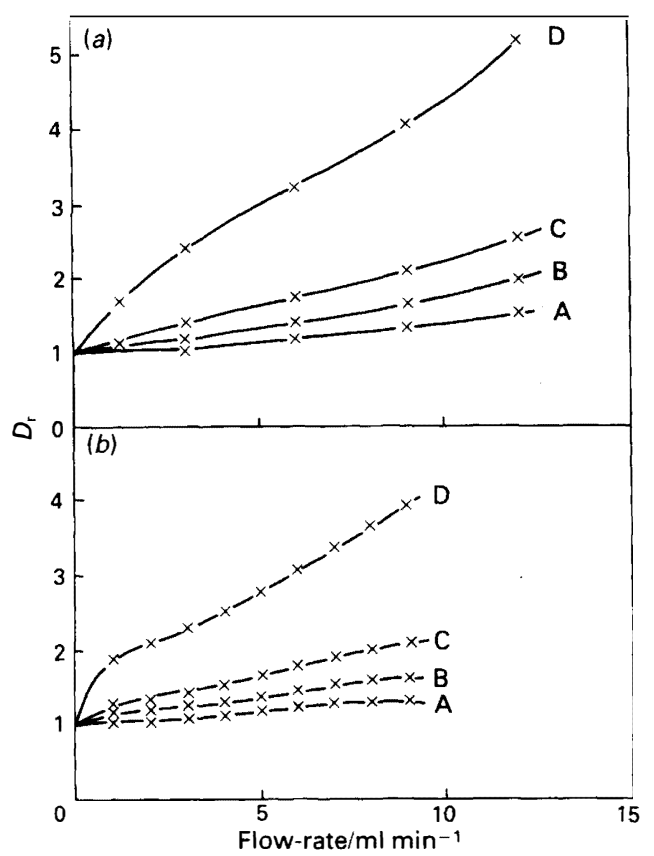

Fig. 15. Variation of response dispersion coefficient $\left(D_{\mathrm{r}}\right)$ with flow-rate for several injection volumes: A, 150; B, 100; C, 70; and D, $30 \mu \mathrm{l}$. (a), Curves predicted and $(b)$, experimental curves

Table 5. Variation of $u_{\text {max }}$. with $V_{\mathrm{i}}$

\begin{tabular}{rcc} 
& \multicolumn{2}{c}{$u_{\text {max }} / \mathrm{ml} \mathrm{min}^{-1}$} \\
\cline { 2 - 3 }$V_{\mathrm{i}} / \mu \mathrm{l}$ & Model & Experimental \\
30 & 6.9 & 4.5 \\
70 & 7.6 & 5.0 \\
100 & 8.0 & 5.4 \\
150 & 8.6 & 6.8
\end{tabular}

measuring the solution flow-rate through the system at pump settings of $200,400,600,800$ and 1000 , using the method described above. The free aspiration rate of the nebuliser via the $4.5 \mathrm{~cm}$ inlet tube was measured.

\section{Results and Discussion}

The mean absorbance - time profile is shown in Fig. 10, and the variation of detector dispersion coefficient with volume injected and flow-rate in Table 2 . These results clearly show the non-ideal behaviour of the atomic absorption detector.

If the single-tank model is applicable then a plot of $\ln \left(A_{\mathrm{m}} / A_{\mathrm{m}}-A\right)$ against $t$ [equation (12)] would be linear. As can be seen from Fig. 11 the plot consists of two linear portions. The initial gradient, $G_{0}$ is $2.86 \mathrm{~s}^{-1}$ and the final gradient, $G_{\infty}$, is $0.064 \mathrm{~s}^{-1}$. The aspiration rate was calculated to be $0.127 \mathrm{ml} \mathrm{s}^{-1}$. Although the single-tank model is clearly not applicable throughout the entire timescale of the experiment, the initial portion of the plot, occupying about $0.7 \mathrm{~s}$ indicates that the model would be applicable up to about $80 \%$ $A_{\mathrm{m}}$. Were the failure of the model due to inadequate amplifier or recorder response time, then this would be most apparent when the signal was increasing rapidly. However, this was not observed.

The two apparently linear sections of the graph of $\ln \left(A_{\mathrm{m}} / A_{\mathrm{m}}-A\right)$ against $t$ suggest that the system response might conform to a compound exponential function containing two exponential terms with very different time constants, corresponding to the gradients $G_{0}$ and $G_{\infty}$. This would be the parallel-tanks model with two tanks (Fig. 1) for which the basic response is given by equation (15), in which $u f_{1} / V_{1}$ is $G_{0}$ (small tank with rapid response) and $u f_{2} / V_{2}$ is $G_{\infty}$ (large tank with slow response)

From Fig. $11, G_{0}$ was found to be $2.86 \mathrm{~s}^{-1}$ and $G_{\infty}, 0.064 \mathrm{~s}^{-1}$ thus $V_{1}=0.44 f_{1}$ and $V_{2}=1.98\left(1-f_{1}\right)$.

A computer was used to generate response curves according to equation (15), for various values of $f_{1}$. These are shown in Fig. 12. Of the values tested, $f_{1}=0.9\left(V_{1}=0.04 \mathrm{ml}, V_{2}=0.2\right.$ $\mathrm{ml})$ gave a good fit. No doubt an even better fit could be obtained by carefully adjusting the parameters of this very flexible model. The effect of the second tank in the model can clearly be seen from Fig. 13, which also shows the curve for a single tank of volume $0.044 \mathrm{ml}$ (the best-fit volume for this model).

\section{Extended-tank Model}

FI-AAS response is described by this model in equation (25), which may be rearranged to give

$$
\ln \left(\frac{A_{\mathrm{m}}}{A_{\mathrm{m}}-A_{\mathrm{p}}}\right)=-\frac{Q}{V}\left(\frac{V_{\mathrm{i}}}{u}\right)
$$

i.e., within the linear range of instrument response, $Q / V$ may be measured as the gradient of a plot of $\ln \left(A_{\mathrm{m}} / A_{\mathrm{m}}-A_{\mathrm{p}}\right)$ against $V_{\mathrm{i}} / u$. Data for such plots taken from the results shown in Fig. 14 are given in Table 3 and show that $Q / V$ is not constant but increases with $u$, as predicted by the model. give

As $Q=q+p u$ (Fig. 7), equation (25) can be re-arranged to

$$
\frac{u}{V_{\mathrm{i}}} \ln \left(\frac{A_{\mathrm{m}}}{A_{\mathrm{m}}-A_{\mathrm{p}}}\right)=\frac{q+p u}{V} \ldots .
$$

Examination of the steady-state absorbances in Table 3 (also shown in Fig. 14) suggested that the relationship between $p$ and $u$ might be $p=u(1-b u)$ where $b$ is a constant. Substitution for $p$ in equation (36) gives

$$
\frac{u}{V_{\mathrm{i}}} \ln \left(\frac{A_{\mathrm{m}}}{A_{\mathrm{m}}-A_{\mathrm{p}}}\right)=\frac{q+u-b u^{2}}{V} \quad \ldots
$$

Values of the left-hand term of equation (37), at constant $V_{\mathrm{i}}$, were tabulated against the nine values of flow-rate in Table 3, 


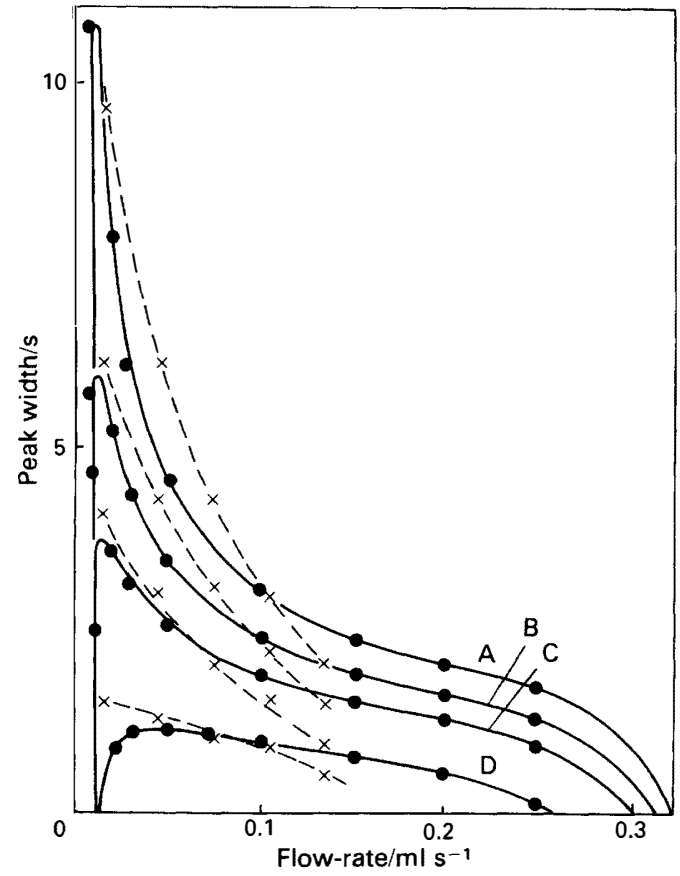

Fig. 16. Solid lines, variation of peak width, $t^{\prime}$, with flow-rate as predicted by the extended-tank model, equation (32) for various volumes injected. $C_{\mathrm{m}}$ is $0.5 \mathrm{mg} \mathrm{l}^{-1} ; A_{1}$ is absorbance 0.1 ; and $t, k, q$ and $V$ are $2.8 \mathrm{~s} \mathrm{ml}^{-1}, 22.9 \mathrm{~A} \mathrm{~s} \mathrm{ml}^{-1} \mathrm{mg}^{-1} 1,0.032 \mathrm{ml} \mathrm{s}^{-1}$ and $0.085 \mathrm{ml}$ respectively. Broken lines indicate the experimental results. A, 150; $\mathrm{B}, 100 ; \mathrm{C}, 70$; and D, $30 \mu \mathrm{l}$

and the best least-squares fit to the general quadratic $y=A+$ $B u+C u^{2}$ was computed. Comparing the empirical results with the model gives $A=q / V ; B=1 / V$; and $C=-b / V$. The results of the calculation are shown in Table 4 .

The mean values of the model parameters are $V=0.085 \mathrm{ml}$, $b=2.8 \mathrm{~s} \mathrm{ml}^{-1}$ and $q=0.032 \mathrm{ml} \mathrm{s}^{-1}$. Some of the model's predictions are examined, using these values.

\section{$\mathrm{u}_{\text {max }}$, flow-rate giving maximum peak height}

$u_{\max }$ varies with $V_{\mathrm{i}}$, as indicated by equation (27). The model parameters obtained give $p=(1-2.8 u), \mathrm{d} p / \mathrm{d} u=-2.8$. After substituting these values into equation (27), the equation was solved for each value of $V_{\mathrm{i}}$ by an iterative procedure using a microcomputer. The resulting values of $u_{\text {max. }}$ are compared with the experimental values in Table 5 .

The model predicts the observed upwards trend of $u_{\max }$. with increasing $V_{\mathrm{i}}$.

\section{Response dispersion}

The variation of $D_{\mathrm{r}}$ with flow-rate is decribed by equation (26). Values calculated using this equation are compared with the experimental values in Fig. 15.

\section{Peak width}

Peak widths computed using the model [equation (32)] are shown in Fig. 16, together with the experimental values. It can be seen that there is good agreement between the experimental values and the calculated values. The interesting result arises that, whilst increasing the flow-rate leads to an increased detector dispersion coefficient it nevertheless results in narrower peaks owing to the more rapid change of absorbance with time.

\section{Conclusions}

The mode of operation of the nebuliser of an atomic absorption spectrometer confers important detector characteristics that must be taken into account when experimental results are interpreted.
The instrument smooths the sample input, and the response always lags behind it: points that are easily overlooked when the instrument is operated in the conventional steady-state mode. In a kinetic situation the consequences become more significant as the concentration - time gradient of the input increases. Thus in FI-AAS the detector's response kinetics may exert a considerable influence over the peak absorbance, so that the ratio of steady state to peak absorbance cannot be routinely employed as an index of sample dilution in the manifold.

The extended-tank model for nebuliser behaviour produces good agreement between experimental and predicted behaviour for the variation of dispersion coefficient with flow-rate and volume injected and of peak width as a function of flow-rate and volume injected. Although the model predicts that the flow-rate at which the maximum peak height will occur as flow-rate is varied increases as the flow increases, there is not particularly good agreement between the numerical values. The results show, however, that a simple model is a valuable aid to understanding the behaviour of a complex system involving several variables. Where exact mathematical treatment fails, such models allow predictions of system behaviour and the continuation of theoretical development. Semi-empirical models, which allow characteristics of the real system to be incorporated into the basic model, may provide an accurate account of the response of the real system. The equations developed should prove useful in the interpretation of results obtained in FI-AAS work.

Financial support for J. M. H. A. by the SERC is gratefully acknowledged.

\section{References}

1. Růžička, J., and Hansen, E. H., "Flow Injection Analysis," Wiley, New York, 1981.

2. Růžička, J., and Hansen, E. H., Anal. Chim. Acta, 1978, 99, 37.

3. Růžička, J., and Hansen, E. H., Anal. Chim. Acta, 1984, 161, 1 .

4. Betteridge, D., Anal. Chem., 1978, 50,832A

5. Taylor, G., Proc. R. Soc. London, A, 1953, 219, 186

6. Tijssen, R., Anal. Chim. Acta, 1980, 114, 71 .

7. van der Berg, J. M. H., Deelder, R. S., and Egbrink, H. G. M., Anal. Chim. Acta, 1980, 114, 91.

8. Reijn, J. M., van der Linden, W. E., and Poppe, H., Anal. Chim. Acta, 1980, 114, 105

9. Reijn, J. M., and Poppe, H., Anal. Chim. Acta, 1983, 145, 59.

10. Vanderslice, J. T., Stewart, K. K., Rosenfield, A. G., and Higgs, D. J., Talanta, 1981, 28, 11

11. Gomez-Nieto, M. A., Luque de Castro, M. D., Martin, A., and Valcarcel, M., Talanta, 1985, 32, 319.

12. Castleman, R., J. Res. Nat. Bur. Stand., 1931, 6, 369

13. Nukiyama, S., and Tanasawa, Y., translated by Hope, E., "Experiments on Atomisation of Liquids in an Air Stream," Defense Research Board, Department of National Defense, Ottawa, Canada, 1950.

14. Lane, W. R., Ind. Eng. Chem., 1951, 43, 1312.

15. Mugele, R. A., and Evans, H. D., Ind. Eng. Chem., 1951, 43, 317.

16. Bitron, M. D., Ind. Eng. Chem., 1955, 43, 23.

17. Hrubecky, H., J. Appl. Phys., 1958, 29, 572.

18. Mercer, T. T., Tillery, M. I., and Chow, H. Y., Am. Ind. Hyg. Assoc. J., 1968, 29, 66.

19. Stupar, J., and Dawson, J. B., Appl. Opt., 1968, 7, 1351.

20. Willis, J. B., Spectrochim. Acta, 1967, 23, 811

21. Cresser, M. S., and Browner, R. F., Appl. Spectrosc., 1980, 34, 365.

22. Cresser, M. S., and Browner, R. F., Spectrochim. Acta, Part B, 1980, 35, 73

23. Cresser, M. S., and Browner, R. F., Anal. Chim. Acta, 1980, 113,33

24. O'Grady, C., Marr, I. L., and Cresser, M. S., Analyst, 1984, $109,1085$.

25. Cresser, M. S., Anal. Proc., 1985, 22, 65. 
26. Green, H. L., and Lane, W. R., "Particulate Clouds," Spon, London, 1957.

27. Browner, R. F., and Boorn, A. W., Anal. Chem., 1984, 56, 780, 875A.

28. Browner, R. F., Boorn, A. W., and Smith, D. D., Anal. Chem., 1982, 54, 1411.

29. Gustavsson, A., Anal. Chem., 1984, 56, 817.

30. Gustavsson, A., Anal. Chem., 1983, 55, 94.

31. Tyson, J. F., Appleton, J. M. H., and Idris, A. B., Anal. Chim. Acta, 1983, 145, 159.

32. Tyson, J. F., and Appleton, J. M. H., Talanta, 1984, 31, 9.
33. Daugherty, R. L., and Franzini, J. F., "Fluid Mechanics with Engineering Applications," Sixth Edition, McGraw-Hill, New York, 1965.

34. Walshaw, A. C., and Jobson, D. A., "Mechanics of Fluids," Second Edition, Longmans, London, 1972.

35. Hidy, G. M., and Brock, H. R., "The Dynamics of Aerocolloidal Systems," Volume 1, Pergamon, Oxford, 1970.

36. Tyson, J. F., Analyst, 1984, 109, 319. 